\title{
Effects of Organic Solvents on Protein Structures: Observation of a Structured Helical Core in Hen Egg-White Lysozyme in Aqueous Dimethylsulfoxide
}

Surajit Bhattacharjya and P. Balaram*

Molecular Biophysics Unit, Indian Institute of Science, Bangalore, India

\begin{abstract}
A partly folded state of hen egg-white lysozyme has been characterized in $50 \%$ DMSO. Low concentrations of DMSO $(<10 \%)$ have little effect on the overall folded conformation of lysozyme as seen from ${ }^{1} \mathrm{H}$ NMR chemical shift dispersion. At increasing DMSO concentrations $(>10 \%)$ a cooperative transition of the structure to a new, partially folded state is observed. This transition is essentially complete by $\sim 50 \%$ DMSO. NMR studies show an overall decrease in chemical shift dispersion with marked broadening of many resonances. A substantial number of backbone and side chain-side chain NOEs suggests the presence of secondary and tertiary interactions in the intermediate state. Tertiary organization of the aromatic residues is also demonstrated by enhanced near-UV circular dichroism and limited exposure of tryptophans as monitored by iodide quenching of fluorescence. The intermediate state exhibits enhanced binding to hydrophobic dyes. Further, the structural transition from this state to a largely unfolded conformation is cooperative. H/D exchange rates of several amide protons and four indole protons of tryptophans (W28, W108, W111, and W123), measured by refolding from $50 \%$ DMSO at different time intervals reveal that protection factors are high for the helical domain, whereas NH groups in the triple stranded antiparallel $\beta$-sheet domain are largely solventexposed. An ordered hydrophobic core in the intermediate state comprising of helix A, helix $B$, and helix $D$ is consistent with the high protection factors observed. The structured intermediate in 50\% DMSO resembles the early kinetic intermediate observed in the refolding of hen egg white lysozyme, as well as a molten globule state of equine lysozyme at low pH. The results demonstrate the potential use of nonaqueous structure perturbing solvents like DMSO to stabilize partially folded conformations of proteins.
\end{abstract}

Key words: folding intermediates; NMR; protein folding; dimethylsulfoxide;
near-UV circular dichroism; lysozyme; molten globules

\section{INTRODUCTION}

The mechanism by which an unstructured polypeptide chain folds efficiently and rapidly into a unique three-dimensional conformation from a very large conformational space available to it within a very short period of timeis a central problem in structural biology. ${ }^{1}$ It is now clear that fol ding of many proteins occur through a limited number of partially folded intermediate species. ${ }^{2-4}$ The detailed structural characterization of such intermediates should provide valuable insights into mechanisms underlying protein folding processes. ${ }^{5,6} \mathrm{Although}$ structural information on these metastable species are inherently difficult to obtain directly, because of the high cooperativity in the folding transition, ${ }^{7}$ techniques have been developed to trap kinetic intermediates. ${ }^{8-10}$ However, results obtained from such studies pose difficulties in interpretation because of the existence of multiple conformations in the unfolded state and effect of final refolding conditions. ${ }^{11,12}$ Consequently, attention has recently turned toward characterizing partially folded states of proteins at equilibrium. It has become evident that the nature and the degree of the structural organization present under equilibrium conditions span the range from largely disordered states to substantially ordered states, depending on the experimental conditions used to unfold or denature proteins. ${ }^{13-16}$ These studies have suggested that unfolding can be induced in a controlled manner, thus providing potential opportunities to study folding intermediates and, thereby, glean knowledge of the folding behavior, structural interactions, and stability of proteins. The stabilization of equilibrium intermediate states has been achieved in some cases by site-specific mutagenesis. ${ }^{17-19}$ We have been exploring the possibility of generating stable, structured intermediates in aqueous organic solvents. Indeed, "solvent engineering" has been suggested as

*Correspondence to: P. Balaram, Molecular Biophysics U nit, Indian Institute of Science, Bangal ore 560012 India

E-mail: pb@mbu.iisc.ernet.in 
a potential approach to modulate protein structures and properties. ${ }^{20}$

The folding of hen egg-white lysozyme, and its structurally homologous milk-derived protein $\alpha$ lactalbumin have been extensively studied. Stable and compact denatured equilibrium states ("molten gl obule" states) have been obtained in various classical denaturing conditions (low $\mathrm{pH}, \mathrm{GuHCl}$, moderately high temperature) for $\alpha$-lactalbumin. ${ }^{14,21}$ By contrast, the unfolding of lysozyme is highly cooperative without any stable intermediates under similar denaturing conditions. ${ }^{21,22}$ However, the transiently populated intermediate of lysozyme obtained in kinetic trapping experiments resembles the equilibrium molten gl obule state of $\alpha$-lactal bumin. ${ }^{23-25} \mathrm{Re}$ cently, nonaqueous solvents have been used as denaturants. ${ }^{26-29}$ In all the above studies, shortchain alcohols (methanol, ethanol, trifluoroethanol [TFE]) have been used as denaturants, which is of some concern in view of the structure-stabilizing properties of the alcohols, in particular, TFE. ${ }^{30-33}$ Such solvents not only stabilize nativelike secondary structures, ${ }^{30,34}$ but also transform other structural elements to nonnative structures. $27,35-38$ These considerations stress the need to identify al ternate solvent systems that do not induce or stabilize structural elements.

Dimethylsulfoxide (DMSO) is known to be a strong structure perturbing agent for proteins and peptides. ${ }^{39,40}$ The denaturant property of DMSO could be attributed to the strong $\mathrm{H}$-bond accepting property of the sulfoxide, whereas two methyl groups presumably interact with the hydrophobic residues of proteins. ${ }^{41,42}$ DMSO could be a denaturant of choice, since many proteins are completely soluble in pure DMSO. ${ }^{39,43}$ A highly unfolded state of hen Iysozyme had been reported in 100\% DMSO. ${ }^{44,45} \mathrm{~A}$ low-resolution infrared (IR), optical rotatory dispersion (ORD) study had indicated a structured species of Iysozyme at DMSO/ $\mathrm{H}_{2} \mathrm{O}$ mixtures. ${ }^{46}$ The present study provides a detailed structural characterization of a highly ordered intermediate state of hen lysozyme in $50 \%$ DMSO $/ \mathrm{H}_{2} \mathrm{O}$ by circular dichroism (CD), fluorescence, nuclear magnetic resonance (NMR), and $\mathrm{H} / \mathrm{D}$ exchange techniques.

\section{MATERIALS AND METHODS}

Hen egg-white lysozyme, deuterated solvents used for NMR experiments were from Sigma Chemical Co. All other chemicals were at least of analytical grade.

\section{Circular Dichroism Experiments}

CD measurements were carried out on a J asco J -500 spectropolarimeter. A 5-mm quartz cell was used for near-ultraviolet (UV) CD experiments. The concentration of Iysozyme was $60 \mu \mathrm{M}$ for all the CD measurements. The pH of the samples were adjusted to a nominal value of 3.0 after addition of DMSO.

\section{Fluorescence Experiments}

Fluorescence quenching experiments were done in a Hitachi fluorimeter. The excitation wavelength for tryptophan were fixed to $295 \mathrm{~nm}$ with a band pass of $5 \mathrm{~nm}$. The concentrations of Iysozyme was $10 \mu \mathrm{M}$. Different aliquots of Nal were added from a concentrated stock (8 M).

$$
\text { A modified Stern-Volmer equation, } 53
$$

$$
\mathrm{Fo} / \Delta \mathrm{F}=\frac{1}{[\mathrm{Q}] \mathrm{f}_{\mathrm{a}} \mathrm{K}_{\mathrm{Q}}}+\frac{1}{\mathrm{f}_{\mathrm{a}}}
$$

where [Q] is Nal concentration, Fo is fluorescence in the absence of quencher, $\Delta \mathrm{F}$ is the change in fluorescence, $\mathrm{f}_{a}$ is the "effective" maximum accessible fluorescence, and $\mathrm{K}_{\mathrm{Q}}$ is the "effective" quenching constant, was used to analyze the fluorescence quenching data, providing estimates of $\mathrm{K}_{\mathrm{Q}}$ and $\mathrm{f}_{\mathrm{a}}$, respectively. ${ }^{53}$

\section{${ }^{1}$ H NMR Spectroscopy}

${ }^{1} \mathrm{H}$ NMR spectra were acquired on a Bruker AMX400 spectrometer (400 MHz) equipped with an Aspect 3000 computer. A low-power (55 dB) irradiation was applied during the relaxation delay to presaturate the water signal. Sodium 3-(trimethylsilyl)propionate- $\mathrm{d}_{4}$ (TSP) was used as internal standard. The $\mathrm{pH}$ of each sample was adjusted to 3.0 (uncorrected for isotope effects or for effects of mixed DMSO/ $\mathrm{H}_{2} \mathrm{O}$ solvents). Protein concentrations used for NMR studies were in the range of 2-6 $\mathrm{mM}$. One-dimensional NMR spectra of lysozyme in the presence of $50 \%$ DMSO show no concentration dependence. Thermal unfolding of lysozyme in 50\% DMSO was studied by recording sets of one-dimensional spectra at various temperatures. Lysozyme with deuterated amide protons was prepared by dissolving the samples in $\mathrm{D}_{2} \mathrm{O}$ at $\mathrm{pH} 3$, heating to $80^{\circ} \mathrm{C}$ for 30 minutes followed by lyophilization.

All two-dimensional high-resolution NOESY and dQF-COSY spectra were collected using time-proportional phase increment methods. All NOESY spectra were collected with mixing time of 200 ms with 64- 72 scans. I $n$ all experiments, the relaxation delay was set to 1.5-2 seconds. Spectral width (6500-7000 $\mathrm{Hz}$ ) were identical in both dimensions. All twodimensional data were zero filled to 1024 points in both dimensions and multiplied by a $\pi / 8$ or $\pi / 16$ shifted sine bell functions prior to Fourier transformation.

\section{Refolding Experiments}

Amide ${ }^{1} \mathrm{H}$ exchange experiments were performed with lysozyme in 50\% DMSO/50\% $\mathrm{D}_{2} \mathrm{O}$ at 12 different time points ranging from 5 minutes to 24 hours, $\mathrm{pH} 3.0$ at $20^{\circ} \mathrm{C}$. Refolding was initiated by eightfold dilution with $\mathrm{D}_{2} \mathrm{O}, \mathrm{pH} 3$, followed by immediate lyophilization to retard deuterium replacement of the slow-exchanging amide protons; ${ }^{28}$ these samples 
were then redissolved to a final concentration of 6 $\mathrm{mM}$ in $\mathrm{D}_{2} \mathrm{O}, \mathrm{pH} 3.0$ and phase-sensitive dQF-COSY spectra were obtained at $25^{\circ} \mathrm{C}^{47}$ within 4 hours. Amide proton intensities were measured from absoIute value of the cross-peaks using Bruker software. Intensities were scaled to COSY cross-peaks of the nonlabile aromatic protons. Amide proton occupancies were normalized to those measured for a sample of hen lysozyme freshly dissolved in $\mathrm{D}_{2} \mathrm{O}$ under identical conditions. Hydrogen exchange rates $\left(k_{e x}\right)$ were fitted to a single-exponential decay equation. Intrinsic exchange rates $\left(\mathrm{k}_{\mathrm{int}}\right)$ of the amide protons in a completely unfolded model of hen lysozyme were calculated taking into account near-neighbor effects, acid and water catalysis as recently been described by Bai et al. ${ }^{48}$ Protection factors $\left(\mathrm{k}_{\mathrm{int}} / \mathrm{K}_{\mathrm{ex}}\right)$ were calculated without considering the effect of DMSO. ${ }^{49}$

\section{Binding of Hydrophobic Molecules to Lysozyme}

In order to examine the binding of hydrophobic molecules to the partially unfolded lysozyme in 50\% DMSO, line-broadening experiments were performed by successively adding small aliquots of a stock solution of lysozyme (5 mM, pH 3) to 5-amino-8naphthalene sulfonic acid (ANSA) and 1-anilino-8naphthalene sulfonate (ANS) $10 \mathrm{mM}, \mathrm{pH} 3$, in $\mathrm{D}_{2} \mathrm{O}$. Two-dimensional intermolecular transferred NOE experiments (TRNOE) were carried out using a mixture of $10 \mathrm{mM}$ 5-amino-8-naphthalene sulfonic acid and $1 \mathrm{mM}$ lysozyme in $\mathrm{D}_{2} \mathrm{O}$ at $\mathrm{pH} 3$, with a mixing time of $200 \mathrm{~ms}$ at $27^{\circ} \mathrm{C}$.

\section{RESULTS \\ Near-UV Circular Dichroism and Fluorescence Quenching}

Although secondary structural transitions are easily amenable to study by far-UV CD (190-250 nm), the high absorbance due to DMSO at low wavelengths preclude far-UV measurements. CD experiments were therefore carried out only in the 270- to 310-nm range, allowing tertiary structural perturbations to be probed. The near-UV CD spectra of lysozyme at three different DMSO concentrations are shown in Figure 1. The CD signals at 287 and $291 \mathrm{~nm}$ of the native lysozyme are assignable to transitions of the tryptophan residues. A substantial increase in the CD signal occurs in 50\% DMSO, with concomitant blueshift of the 287-nm CD band, which clearly indicates sequestering of the tryptophan(s) to a more structured environment with a consequence of motional restriction. The blue shift of the $287-\mathrm{nm}$ band suggests the environment of a group of tryptophan residues are more affected compared to those responsible for 291-nm CD signal. The intensity of the 291-nm band, however, is enhanced without any shift of the band position.

Similar enhancements of near-UV CD ellipticities and a blue shift in emission maxima of the trypto-

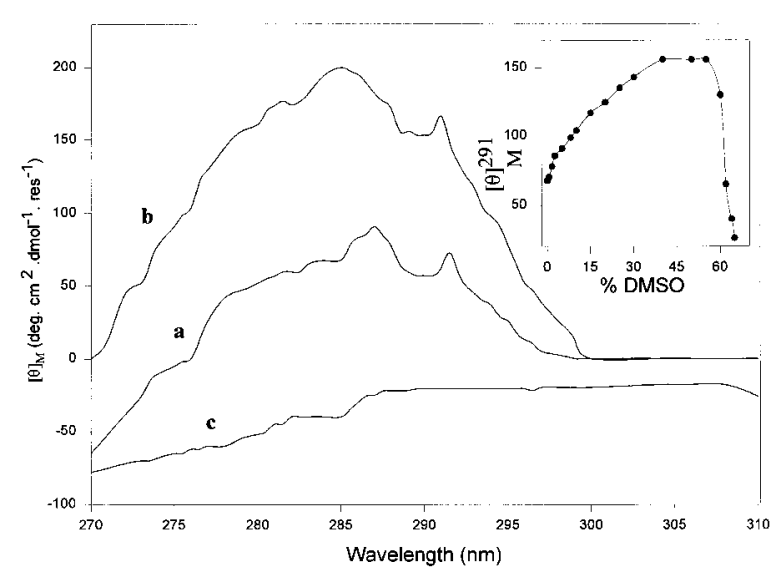

Fig. 1. Near-UV-CD spectra of hen egg white lysozyme at $\mathrm{pH}$ 3. a: unbuffered $\mathrm{H}_{2} \mathrm{O}$ native state. b: $50 \%$ DMSO- $\mathrm{H}_{2} \mathrm{O}$. c: $70 \%$ DMSO- $\mathrm{H}_{2} \mathrm{O}$. Inset: Change in molar ellipticity (deg $\cdot \mathrm{cm}^{2} \cdot \mathrm{dmol}^{-1}$. $\mathrm{res}^{-1}$ ) at $291 \mathrm{~nm}$ as a function of DMSO concentrations.

phan residues have been reported for a molten globulelike state of a homologous protein apoequine lysozyme in $\mathrm{GuHCl}^{50}$ and also during its thermal unfolding. ${ }^{51}$ It has also been reported that the tryptophan residues of thermally denatured lysozyme show reduced accessibility toward flavin dyes in dynamic nuclear polarization experiments. ${ }^{52} \mathrm{At}$ higher DMSO concentrations $\sim 70 \%$ there is complete loss of near-UV CD signal due to unfolding of the protein structure. Titration of Iysozymewith different DMSO concentrations indicates a broad structural transition around $20-25 \%$ DMSO, which is essentially complete by $50 \%$ DMSO (Fig. 1, inset). The small increase in ellipticity at low concentrations of DMSO may be a consequence of preferential binding of the organic cosolvent near the active site of Iysozyme, which contains two exposed tryptophan residues. This conjecture is also supported by changes in chemical shifts of the active site tryptophan residues at low concentration of DMSO in NMR studies (see below). A second sharp transition occurs at DMSO concentrations $>50 \%$ to achieve a largely unfolded state.

The surface accessibility of tryptophan residues are probed by $\mathrm{Nal}$ quenching experiments. The quenching behavior of lysozyme is shown in Figure 2 at three different conditions. The native state of lysozyme experiences some quenching due to the two solvent-exposed active sitetrytophan residues (W62, W63), which is in accord with the previous results. ${ }^{53}$ All thesix tryptophan residues are equally quenched, suggesting a complete exposure in the unfolded state at $6 \mathrm{M} \mathrm{GuHCl}$. On the other hand, the modified Stern-Volmer plot in 50\% DMSO indeed indicates that the tryptophans are less accessible to quencher as compared to native lysozyme and the highly denatured state at $6 \mathrm{M} \mathrm{GuHCl}$. The "effective" fractional maximum accessible fluorescence $\left(\mathrm{f}_{\mathrm{a}}\right)$ and the 


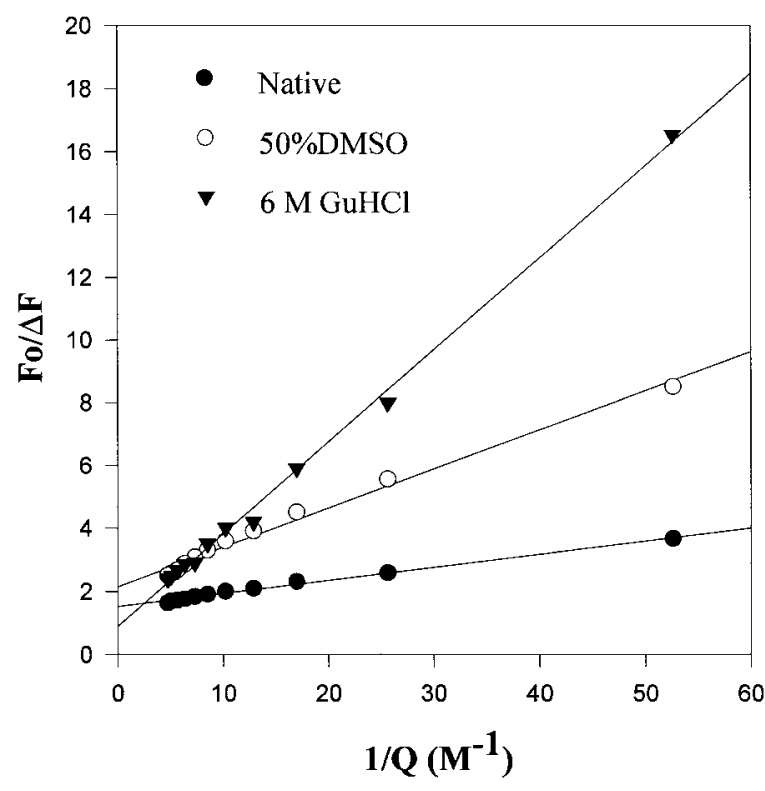

Fig. 2. Modified Stern-Volmer plot of the quenching of tryptophan fluorescence of lysozyme in three different structural states by iodide. Nal concentrations ranged from 0.019 to $0.20 \mathrm{M}$.

"effective" quenching constant $\left(\mathrm{K}_{\mathrm{Q}}\right)$ are estimated to be, 0.66 and $25 \mathrm{M}^{-1}$ in the native state of Iysozyme, 0.50 and $15 \mathrm{M}^{-1}$ in the $50 \%$ DMSO state and 1.1, 3.0 $\mathrm{M}^{-1}$ in the unfolded state at $6 \mathrm{M} \mathrm{GuHCl}$, respectively. The values obtained for the native and unfolded state in $6 \mathrm{M} \mathrm{GuHCl}$ of, Iysozyme are in good agreement with the earlier results with the exception of $\mathrm{K}_{\mathrm{Q}}$ for native lysozyme which is higher as compared to previous published value. ${ }^{53}$ Since the $\mathrm{K}_{\mathrm{Q}}$ is highly sensitive to the experimental conditions, this discrepancy may be attributed to the different salt concentrations used in the two studies. Taken together, these results indicate a more structured environment of the tryptophan residues in the 50\% DMSO state of lysozyme.

\section{NMR Studies \\ Chemical shift dispersion of Iysozyme}

Figure 3 compares the chemical shift dispersion of the three different states of lysozyme: (a) $\mathrm{D}_{2} \mathrm{O}$ (native state), (b) $50 \%$ DMSO, and (c) $80 \%$ DMSO. The nativestate lysozyme spectrum (Fig. 3a) is characteristic of a completely folded protein with wide chemical shift dispersion and many strongly hydrogen bonded amide resonances in the region of $7.8 \mathrm{ppm}$ to $9.3 \mathrm{ppm}$. In addition, the spectrum shows many resonances with characteristic chemical shift that are clearly isolated and well demarcated from the broad envelopes. The most upfield-shifted resonances are from the side chains of aliphatic residues due to their susceptibility to ring current effects of the nearby aromatic residues. The two upfieldshifted aromatic ring proton resonances, W28 C5H
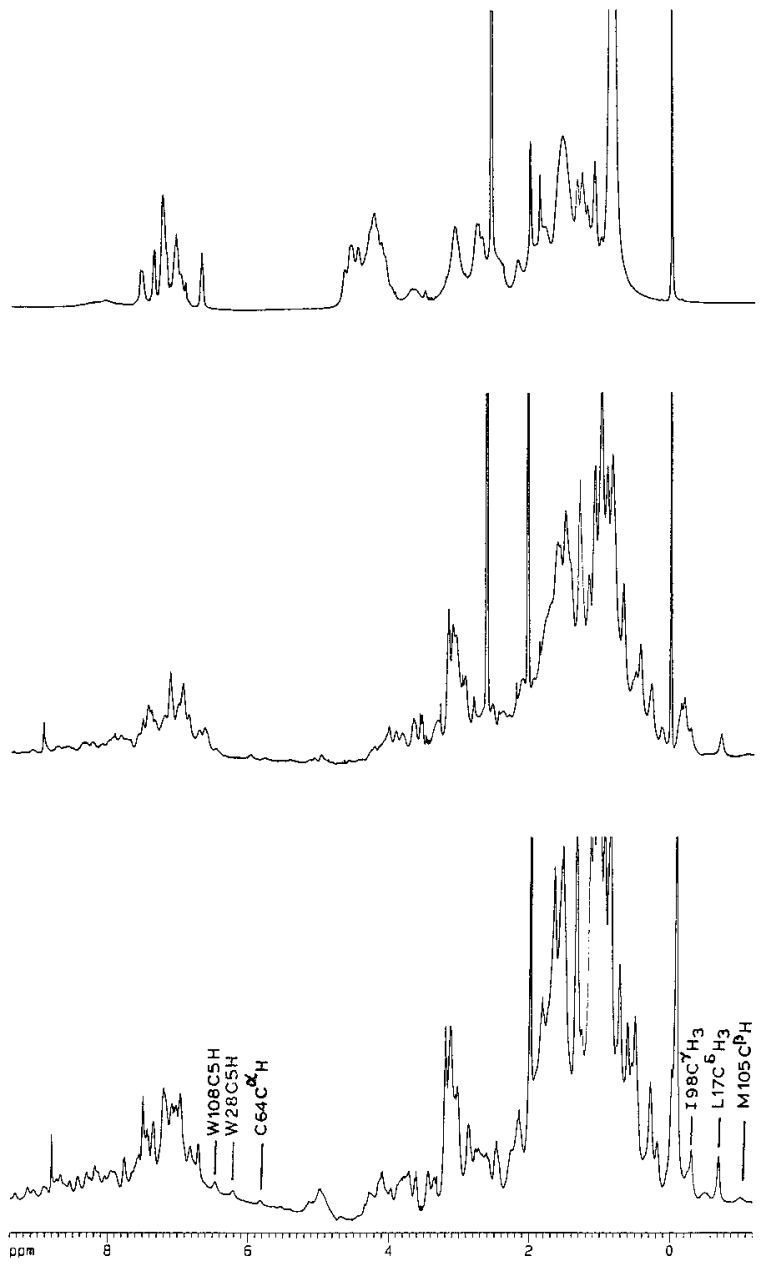

Fig. 3. Proton NMR spectra $(400 \mathrm{MHz})$ of hen egg white lysozyme. a: $\mathrm{D}_{2} \mathrm{O}$, native state. b: $50 \%$ DMSO- $\mathrm{D}_{2} \mathrm{O}$. c: $80 \%$ DMSO- $\mathrm{D}_{2} \mathrm{O}$. Specific resonances that serve as probes of structure are marked in the native state spectrum.

(6.29 ppm) and W108 C5H (6.50 ppm) as well as the $\mathrm{C} 2 \mathrm{H}$ proton of $\mathrm{H} 15$ and the relatively downfieldshifted $\mathrm{C}^{\alpha} \mathrm{H}$ resonance of $\mathrm{C} 64^{47}$ are potentially useful in monitoring structural changes of the native protein.

\section{The partially fol ded state in 50\% DMSO}

The overall chemical shift dispersion in the onedimensional ${ }^{1} \mathrm{H}$ NMR spectrum of lysozyme in $50 \%$ DMSO at pH 3, (Fig. 3b) is reduced compared to the native state with broadening of many of the resonances, particularly those of the $\mathrm{C} 5 \mathrm{H}$ protons of $\mathrm{W} 28$ and $\mathrm{W} 108$, the $\mathrm{C} 4 \mathrm{H}$ of $\mathrm{H} 15$ and the $\mathrm{C}^{\alpha} \mathrm{H}$ of $\mathrm{C} 64$ (see Fig. 5). However, the observation of high field aliphatic proton resonances suggests persistence of ring current effects in the 50\% DMSO state. These resonances broaden and move downfield compared to the native state, a feature particularly notable for the $\mathrm{M} 105 \mathrm{C}^{\beta} \mathrm{H}, \mathrm{CH}_{3}(-0.97$ and 0 ppm, respectively in native lysozyme) and $\mathrm{L}^{8} \mathrm{C}^{8} \mathrm{H}_{3}(-0.05 \mathrm{ppm}$ in 
native lysozyme) protons. The resonances in the region of 8.0-9.0 ppm, arising from the solvent shiel ded amide protons show a dramatic decrease in intensity (Fig. 3b). A similar pattern of line-broadening of side chain resonances has been observed in the molten gl obule state of $\alpha$-lactalbumin ${ }^{54}$ and partially folded state of apoequine lysozyme, ${ }^{50}$ and attributed to the conformational exchange process occurring between different populations in the intermediate time scale $\left(10^{2}-10^{3} \mathrm{~s}^{-1}\right)$. The dispersion of the $\mathrm{C}^{\alpha} \mathrm{H}$ resonances are also reduced compared to the native structure (Fig. 3b), but the resonances are far from the expected values for residues in a random-coil polypeptide chain. ${ }^{55} \mathrm{An}$ analysis of COSY spectra in $50 \%$ DMSO shows that most of the $\mathrm{C}^{\alpha} \mathrm{H}$ resonances are distributed in the range of $4.8 \mathrm{ppm}$ to $3.6 \mathrm{ppm}$ (data not shown). The predominantly upfield position (4.45-3.88 ppm) relative to the random coil values (4.63-4.11 ppm) is suggestive of the presence of residual $\alpha$-helical secondary structure ${ }^{56}$ in Iysozyme in 50\% DMSO; the relative paucity of $\mathrm{C}^{\alpha} \mathrm{H}$ resonances shifted downfield (5.10-4.47 ppm) from the random coil values suggests the probable absence of well-defined $\beta$-sheet structure ${ }^{56}$ in lysozyme in $50 \%$ DMSO.

\section{The unfolded state in $\mathbf{8 0} \%$ DMSO}

In $80 \%$ DMSO the chemical shift dispersion is reduced further compared to that in 50\% DMSO (Fig. 3c). All the ring current-affected aliphatic proton resonances are shifted downfield toward the typical random coil values. ${ }^{55}$ The chemical shift dispersion of the $129 \mathrm{C}^{\alpha} \mathrm{H}$ protons are diminished to $0.8 \mathrm{ppm}$ and that of the amide protons, to $0.7 \mathrm{ppm}$ in $80 \%$ DMSO/20\% $\mathrm{H}_{2} \mathrm{O}$ (data not shown). Almost all the amide protons exchange completely in $\mathrm{D}_{2} \mathrm{O}$ suggesting a "floppy structure" held by four disulfide bonds. However, the presence of few NH/NH NOEs in the two-dimensional NOESY spectra (see Fig. 8b) indeed suggests that some local structural interactions arestill present in the unfolded protein. Earlier studies have shown that lysozyme is highly unfolded when dissolved in neat DMSO with all the disulfide bonds reduced. ${ }^{44}$ The sidechain resonances are sharper (Fig. 3c) compared to either native or the $50 \%$ DMSO state, which is probably a consequence of greater conformational flexibility in the unfolded state.

\section{Nature of denaturation induced by DMSO}

Figure 4 shows the lowfield resonances in the one-dimensional NMR spectra of lysozyme in $\mathrm{D}_{2} \mathrm{O}$ at different DMSO concentrations. In the absence of DMSO, the spectrum recorded after 1 hour of exchange (bottom spectrum), three of the six indole $\mathrm{NH}$ protons are readily recognized by comparison with previously assigned spectra. ${ }^{47}$ These correspond to W123,W111, and W108; all of which are well separated from others and have sl ow exchange rate, thus serving as useful probes to monitor structural perturbations induced by DMSO. Several slowly exchanging backbone amide protons are also present. The indole NH groups of W62 and W63, which are active site residues and solvent-exposed, exchange rapidly with $\mathrm{D}_{2} \mathrm{O}$ and are not observed. In the presence of 3-5\% DMSO, the chemical shifts of most of the resonances are not perturbed, indicating that there is no overall change in the conformation of lysozyme. However, the indole proton resonances of W108 is shifted to lowfield. In DMSO titration experiments carried out in water (data not shown), the indole resonances of the solvent exposed residues W62 and W63, also move downfield. The downfield shift of the indole protons from the active site tryptophan residues suggests a probable binding site of DMSO near the active site of the enzyme. Similar chemical shift differences of these resonances, observed in the presence of inhibitor (GICNAc) ${ }_{3}$ or urea ${ }^{57}$ and trifluoroethanol, ${ }^{28}$ have been attributed to the binding of inhibitor or denaturant molecules to the active site of lysozyme, in the native state. The binding of DMSO to the native state of lysozyme has also been demonstrated by soaking lysozyme crystals at $15 \%$ DMSO in a neutron diffraction experiments. ${ }^{42}$ The native state has been retained at 15\% DMSO in crystals; however, in solution the native structure is substantially perturbed at the same concentration of DMSO. At higher concentrations of DMSO ( 10\% and above), broadening of many isolated resonances are observed (Figs. 3 and 4). Line-broadening is not a consequence of aggregation of protein molecules, since even at very low protein concentrations (0.1 $\mathrm{mM}$ ) the linewidths are unchanged; (one-dimensional spectra obtained after accumulation for 8 hours). We chose two relatively sharp resonances $\left(\mathrm{H} 15 \mathrm{C} 2 \mathrm{H}\right.$ and $\left.\mathrm{C} 64 \mathrm{C}^{\alpha} \mathrm{H}\right)$ to represent residues in both structural domains of lysozyme, to monitor changes in these regions as a function of added denaturant concentration. It may be noted that there is a significant difference in the linewidths of $\mathrm{H} 15 \mathrm{C} 2 \mathrm{H}(6.5 \mathrm{~Hz})$ and $\mathrm{C} 64 \mathrm{C}^{\alpha} \mathrm{H}(12 \mathrm{~Hz})$ in the native protein presumably as a consequence of greater mobility of the $\mathrm{H} 15$ side chain relative to the backbone. H15 is in the helical domain, whereas C64 is present in the junction between the $\beta$ sheet and a connecting long loop region. Figure 5 shows the changes in the line widths of $\mathrm{H} 15 \mathrm{C} 2 \mathrm{H}$ and $\mathrm{C} 64 \mathrm{C}^{\alpha} \mathrm{H}$ protons. At DMSO concentrations of $<10 \%$, linewidths are unaffected, while there is gradual broadening of both resonances in the range of $10-30 \%$, with saturation being reached at higher concentrations. This suggests that the DMSO-induced denaturation of Iysozyme is essentially a two-state transition, proceeding from the native to the partially unfolded state at 50\% DMSO, with only the population of the unfolded species increasing without the appearance of further intermediate species. 

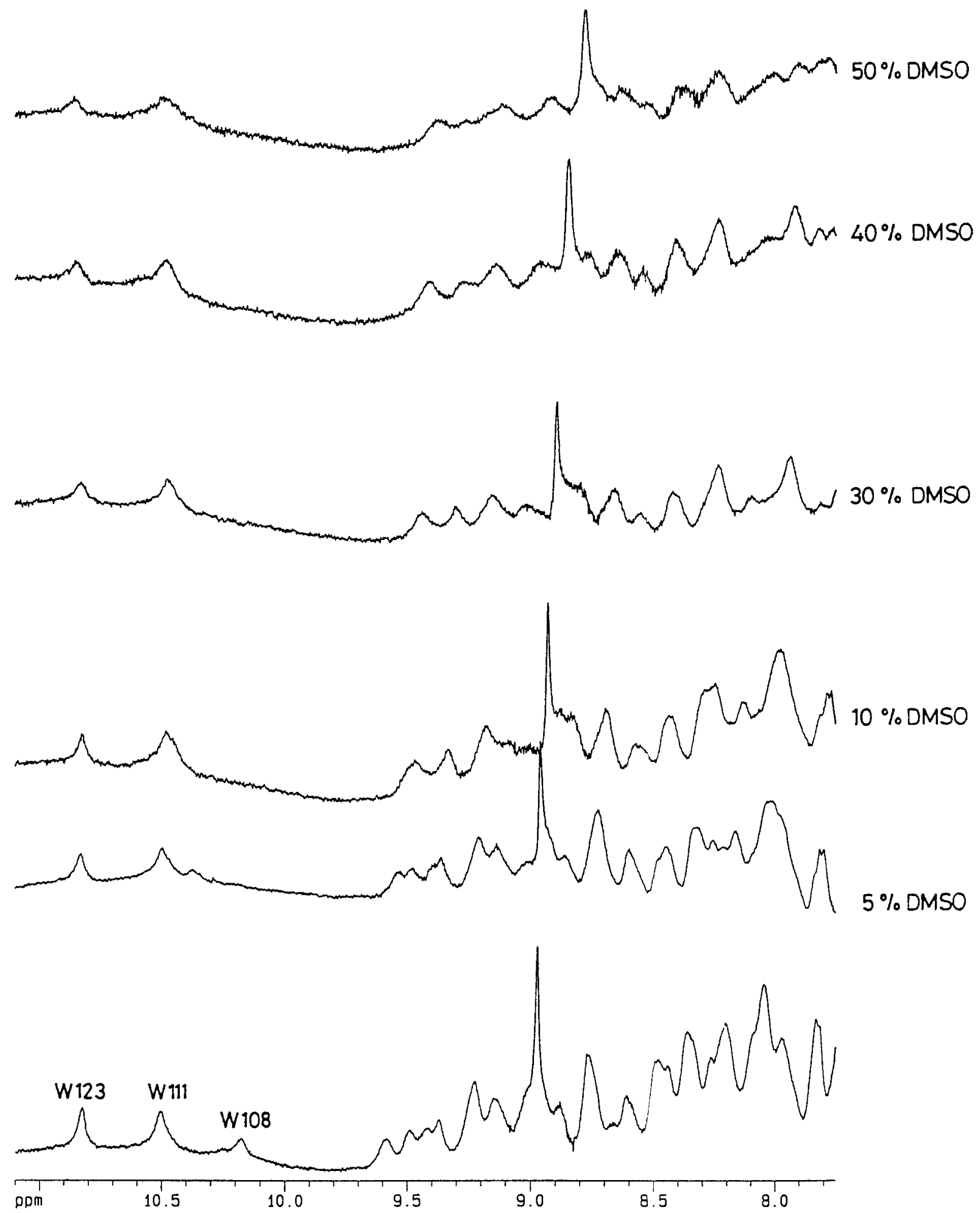

Fig. 4. Lowfield region of 1-D ${ }^{1} \mathrm{H}$ NMR spectra of hen egg white lysozyme in $\mathrm{D}_{2} \mathrm{O}$ and DMSO- $\mathrm{D}_{2} \mathrm{O}$ mixtures, $\mathrm{pH} 3,298 \mathrm{~K}$ at increasing DMSO concentrations. Indole NH proton of W123, W111, and W108 are marked. 

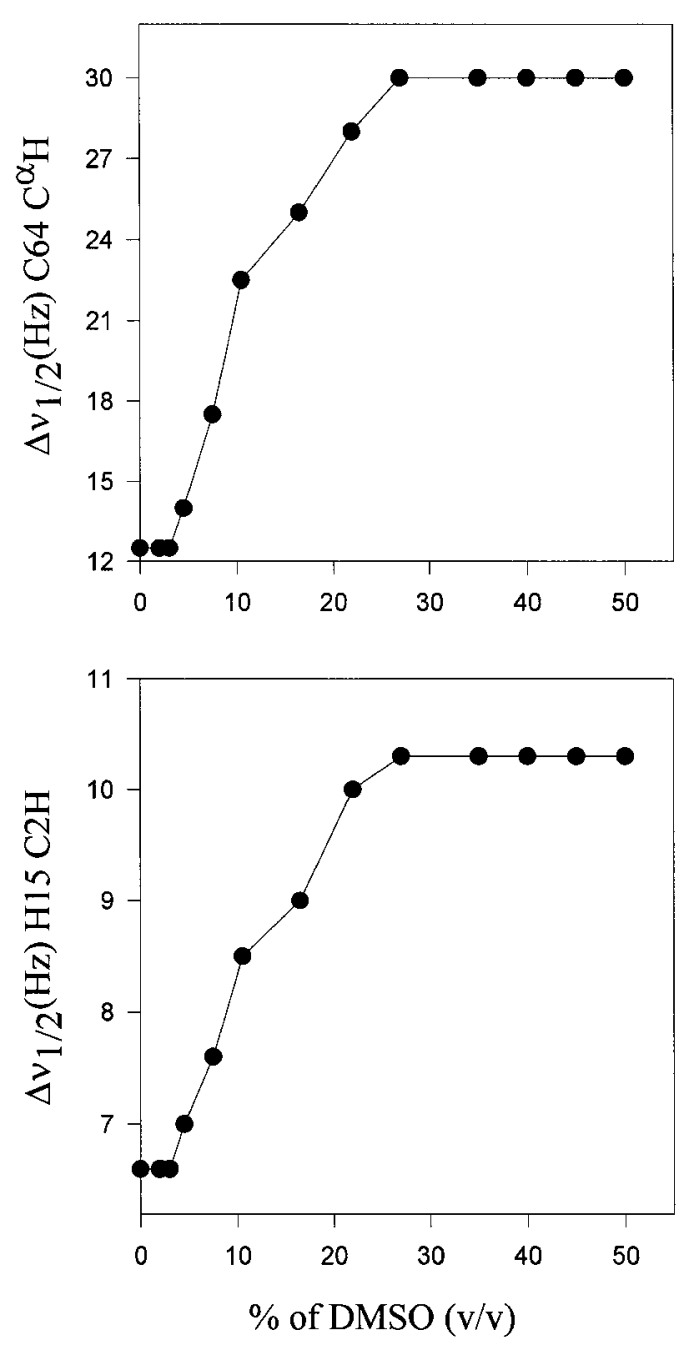

Fig. 5. Transition to the intermediate state of lysozyme in 50\% DMSO monitored by change in linewidth at half-height $\left(\Delta v_{1 / 2}\right)$ and as a function of increasing concentrations of DMSO. Top: C64 $\mathrm{C}^{\alpha} \mathrm{H}$. Bottom: $\mathrm{H} 15 \mathrm{C} 2 \mathrm{H}$.

\section{Thermal unfolding of the intermediate state of Iysozyme in 50\% DMSO}

The thermal unfolding of the residual structure present in lysozyme in 50\% DMSO has been carried out by one-dimensional ${ }^{1} \mathrm{H}$ NMR at different temperatures (Fig. 6). With increase in temperature, there is overall sharpening of several resonances. Concomitantly, another set of resonances appear due to a population of unfolded structures. This is typified by the two sets of resonances for $\mathrm{H} 15 \mathrm{C} 2 \mathrm{H}$, arising due to interconversion between the structured DMSO state and the thermally unfolded state in slow exchange. The cooperative thermal unfolding of native lysozyme has also been characterized by a slow exchange between folded and unfolded species, typified by the doubling of the $\mathrm{H} 15 \mathrm{C} 2 \mathrm{H}$ resonance. 22 The similarity in the thermal unfolding is probably a consequence of many nativelike interactions in-
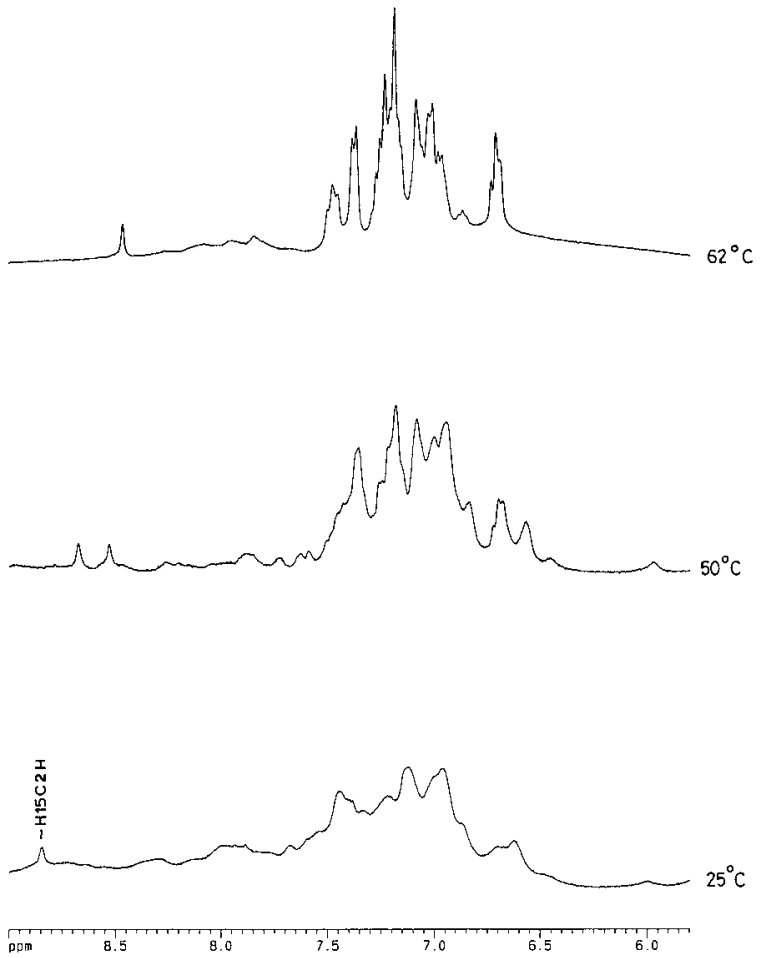

Fig. 6. Lowfield region of ${ }^{1} \mathrm{H}$ NMR spectra of hen lysozyme at $50 \%$ DMSO at three different temperatures. The single $\mathrm{H} 15 \mathrm{C} 2 \mathrm{H}$ resonance is marked. The observation of two $\mathrm{H} 15 \mathrm{C} 2 \mathrm{H}$ resonances at $50^{\circ} \mathrm{C}$ indicates the midpoint of the thermal transition.

volved in stabilizing the intermediate state formed at $50 \%$ DMSO.

Hence disruption of the residual structure occurs in a cooperative way. However, the thermal stability of the intermediate state has been dramatically reduced with $a T_{m}$ of $50^{\circ} \mathrm{C}$ as compared to the native lysozyme $\left(T_{m} 77^{\circ} \mathrm{C}\right)$. Thermal melting monitored by near UV CD experiments also indicate a broadly cooperative loss of residual structure instead of a gradual loss (data not shown).

\section{Evidence for secondary structural el ements in lysozyme in 50\% DMSO}

Through space information from nuclear Overhauser effects (NOEs) are extremely useful in identifying regular structural elements in the proteins. In this regard, theNH/NH NOEs in the NOESY spectra are of particular value in investigating the presence of secondary structure, either helices or turns in the structured DMSO intermediate of Iysozyme. ${ }^{55} \mathrm{Fig}$ ure 7 compares the NOESY spectra in the NH/NH region of the $50 \%$ DMSO state of Iysozyme and the largely unfolded state in $100 \%$ DMSO. The wider chemical shift dispersion and the greater number of intense NOEs in the former are clearly apparent. Many of the $\mathrm{NH} / \mathrm{NH}$ NOEs in 50\% DMSO have intensities comparable to the short intraresidue NOE s from the aromatic ring protons. However, care 
(a)

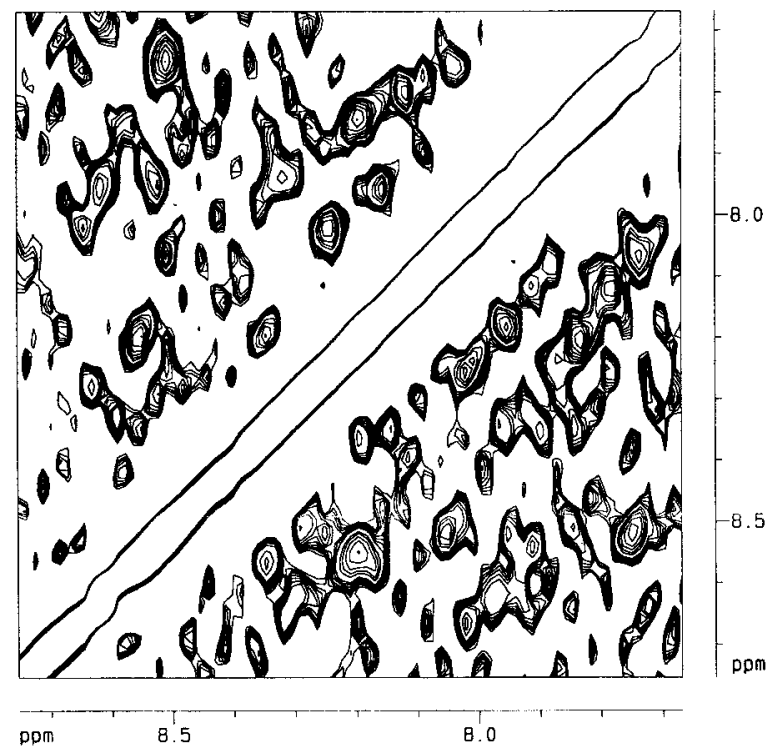

(b)

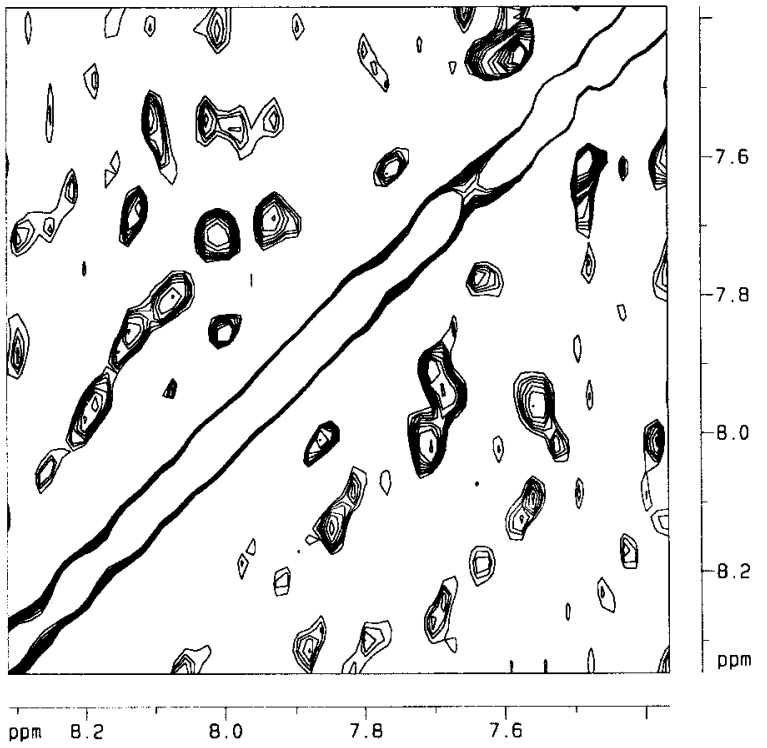

Fig. 7. Partial two-dimensional NOESY spectra (mixing time $200 \mathrm{~ms}, 310 \mathrm{~K}$ ), NH/NH region of lysozyme. a: $50 \%$ DMSO $/ \mathrm{H}_{2} \mathrm{O}$. b: $100 \%$ DMSO.

should betaken in interpreting the observed $\mathrm{NH} / \mathrm{NH}$ NOEs alone, since short $\mathrm{d}_{\mathrm{NN}}$ distances are characteristic of helices, turns and also cross-strand interaction. ${ }^{58}$ The $\mathrm{NH} / \mathrm{NH}$ NOE s are more intense and large in number than in $\mathrm{C}^{\alpha} \mathrm{H} / \mathrm{NH}$ NOEs (data not shown) indicative of persistent helical structure in the $50 \%$ DMSO state of lysozyme. The $\mathrm{C}^{\alpha} \mathrm{H} / \mathrm{C}^{\alpha} \mathrm{H}$ NOE s, which are diagnostic of the antiparallel $\beta$-sheet structure in native aqueous lysozyme, ${ }^{47}$ are not observed in the intermediate state of lysozyme, suggesting the preferential loss of $\beta$-sheet structures in 50\% DMSO (spectra not shown).

\section{Inter-sidechain interactions in the structured DMSO intermediate}

Interside-chain interactions are of great importance in determining the tertiary fold of proteins. NOEs between aromatic ring protons and the sidechain protons of aliphatic residues offer a convenient means of studying tertiary interactions in proteins. Two-dimensional NOESY spectra showing NOE connectivities between the aromatic ring protons and the sidechain protons of the aliphatic residues of Iysozyme in $100 \% \mathrm{D}_{2} \mathrm{O}$ and in $50 \%$ DMSO are shown in Figure 8. Some of the long-range NOEs are marked in the $\mathrm{D}_{2} \mathrm{O}$ spectrum as obtained from the earlier assignment. ${ }^{47}$ The NOESY spectrum in $50 \%$ DMSO is devoid of these characteristic long-range NOEs, indicating the disruption of tertiary interactions typical of the native state. In 50\% DMSO chemical shifts of some ring current-shifted methyl protons $\left(\mathrm{M} 105 \mathrm{C}^{\beta} \mathrm{H}, \mathrm{L} 17 \mathrm{C}^{\delta} \mathrm{H}, 198 \mathrm{C}^{\gamma} \mathrm{H}\right)$ are less perturbed, facilitating their assignments by comparison with the native state spectrum. However, the number of NOEs as well as the dispersion of chemical shifts are reduced in 50\% DMSO. The preservation of a substantial number of NOEs between the side-chain protons indicates the persistence of some hydrophobic interactions. Some of these aliphatic resonances also show small upfield-shifts. This may imply a more structured environment in the vicinity of the aromatic residues that give rise to the ring currents. Notably, few new NOEs from W28 C5H to some unassigned side-chain protons of aliphatic residues are also observed in the 50\% DMSO state. This could be tentatively interpreted as a consequence of the local immobilization of the tryptophan residue in a new nonnativeenvironment. This conclusion is consistent with the enhancement of near UV-CD ellipticities and restricted quenching of the tryptophan residues in the $50 \%$ DMSO state.

\section{Binding of hydrophobic molecules to lysozyme in 50\% DMSO}

A concentration-dependent line broadening of the aromatic resonances of 5-amino-8-naphthalene sulfonic acid (ANSA) as well as 1-anilino-8-naphthalene sulfonate (ANS) has been observed when titrated with lysozyme in 50\% DMSO (Fig. 9). The proton resonances of the probes are broadened extensively as a result of binding to the structured intermediate state of Iysozyme, whereas titration with native lysozyme does not cause any broadening effect (Fig. 9). However, in the case of ANS at low $\mathrm{pH}$, the ANS-Iysozyme complex precipitates. The hydrophobic environment of the binding site in the intermediate state of Iysozyme in DMSO has been confirmed by observation of intermol ecular NOE s from the ring 
(a)

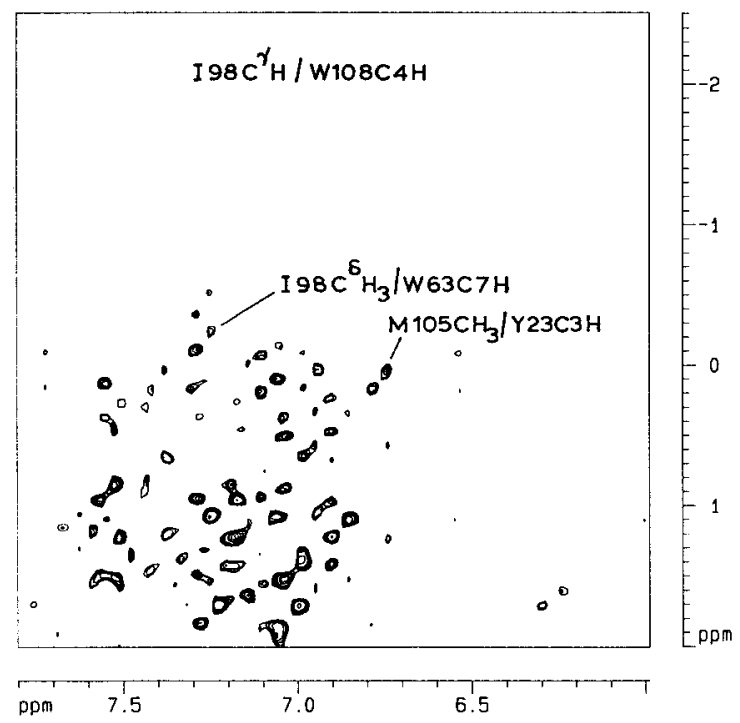

Fig. 8. Partial two-dimensional NOESY spectra (mixing time $200 \mathrm{~ms}, 310 \mathrm{~K}$ ) showing side chain-side chain NOEs (aromatic ring protons to aliphatic side-chain protons) of lysozyme. $\mathbf{a}: \mathrm{D}_{2} \mathrm{O}$.
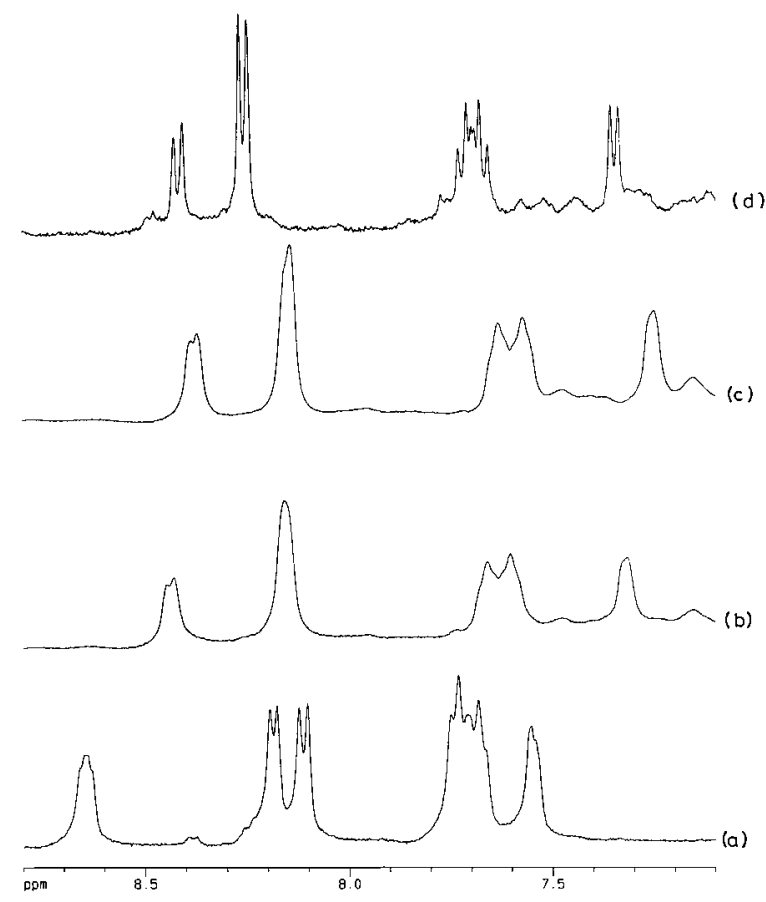

Fig. 9. Aromatic proton resonances $(400 \mathrm{MHz})$ of 5-amino-8naphthalene sulfonic acid (ANSA) in 50\% DMSO- $\mathrm{D}_{2} \mathrm{O}$, titrated with various concentrations of lysozyme in $50 \%$ DMSO. a: Free ANSA (10 mM, pH 3.0). b: $0.1 \mathrm{mM}$ lysozyme in 50\% DMSO, pH 3. c: 1 mM lysozyme in 50\% DMSO, pH 3. d: $3 \mathrm{mM}$ ANSA and $1 \mathrm{mM}$ lysozyme in $\mathrm{D}_{2} \mathrm{O}, \mathrm{pH} 3$.

protons of ANSA to the side-chain protons of the al iphatic residues of the protein (Fig. 10). The intraring NOE s in ANSA in the bound state are negative in sign, indicative of an increased rotational correlation (b)

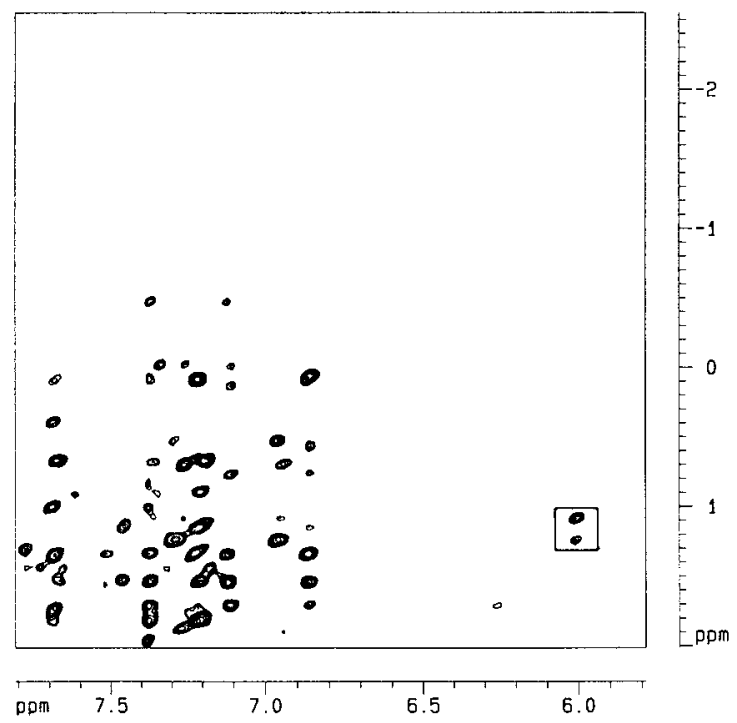

b: $50 \%$ DMSO- $\mathrm{D}_{2} \mathrm{O}$. The backbone amide protons are exchanged out with $\mathrm{D}_{2} \mathrm{O}$ by heating the samples in $80^{\circ} \mathrm{C}$ followed by lyophilization. Two new NOEs from W $28 \mathrm{C} 5 \mathrm{H}$ are boxed.

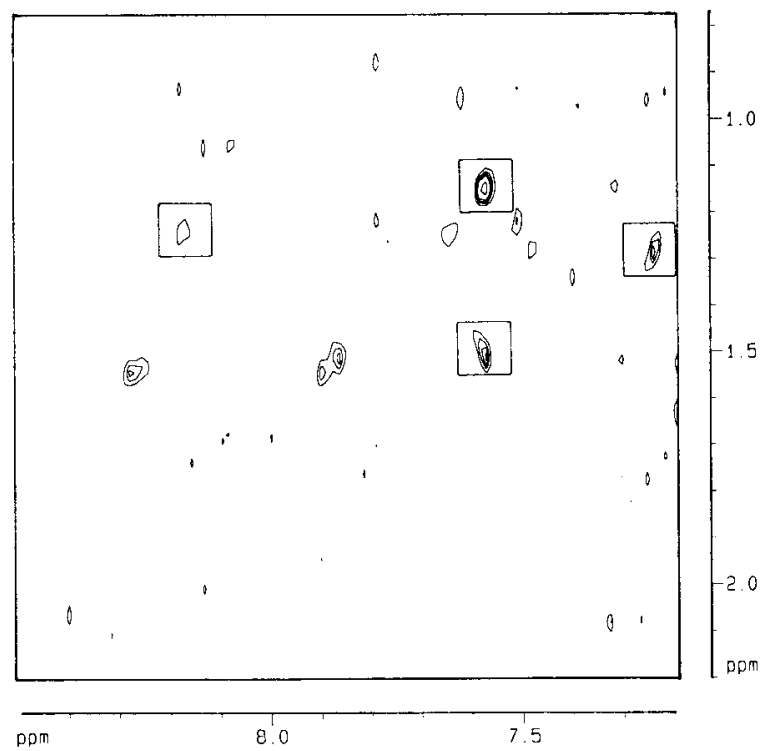

Fig. 10. Partial two-dimensional NOESY spectra (mixing time $200 \mathrm{~ms}, 298 \mathrm{~K}$ ) indicating intermolecular NOEs (in box) between the aromatic ring protons of the hydrophobic dye ANSA and aliphatic side-chain protons of lysozyme in $50 \% \mathrm{DMSO} / \mathrm{D}_{2} \mathrm{O}$, at $\mathrm{pH} 3$.

time, confirming immobilization of the probe on binding to the protein (data not shown).

\section{Structural analysis of the structured intermediate state by H/D exchange}

$\mathrm{H} / \mathrm{D}$ exchange experiments and protection factor measurement for amide protons are widely used to identify structurally well protected $\mathrm{NH}$ protons of the protein folding intermediates, either kinetic or 


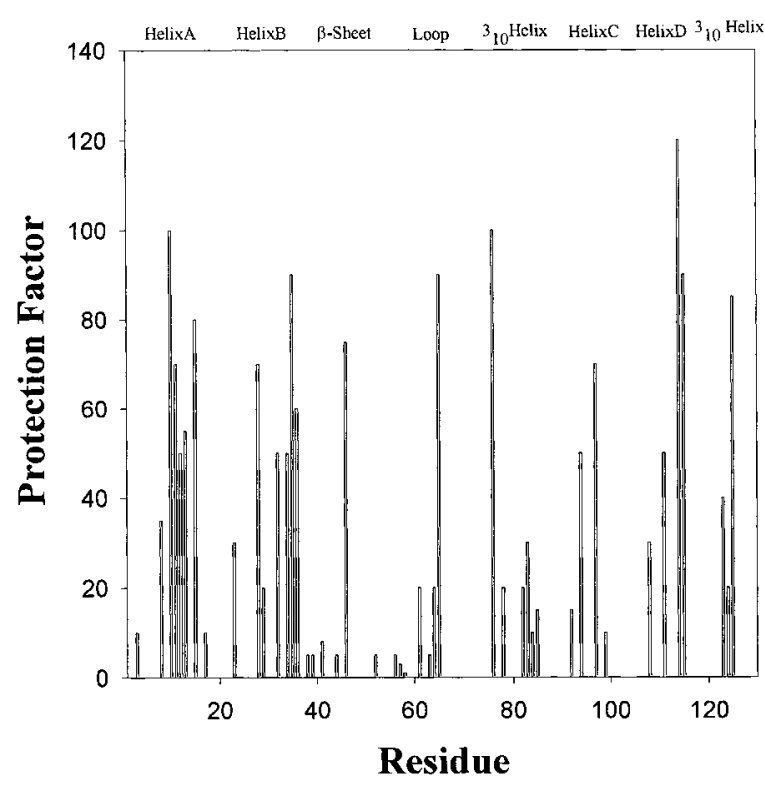

Fig. 11. Bar diagram showing distribution of protection factors of the amide protons of hen lysozyme in $50 \%$ DMSO. Regions of secondary structure in the native state are marked at the top.

equilibrium. ${ }^{59}$ The protection of amide protons against exchange with $\mathrm{D}_{2} \mathrm{O}$ is a consequence of hydrogen bonding or due to steric barriers imposed by tertiary contacts or both. Therefore, the protection of $\mathrm{NH}$ protons either backbone amide protons or indole $\mathrm{NH}$ protons can provide evidence for persistent secondary structure as well as side chain-side chain interactions.

$\mathrm{H} / \mathrm{D}$ exchange experiments were performed from the DMSO state of Iysozyme at 12 different time points ranging from 3 minutes to 24 hours and the exchange rate of 50 amide protons and 4 indole protons (W28, W108, W111, W123) can be monitored under our experimental conditions. The effect of DMSO on the exchange rate of amide protons are not taken into consideration since, at low $\mathrm{pH}(\mathrm{pH} \leq 3.0)$ the effect of organic solvents on the intrinsic exchange of amide protons is negligible. ${ }^{60,61}$ Recently, the effect of DMSO on the exchange rate of amide protons had been investigated in monomeric melittin. ${ }^{49}$ This study showed even at $95 \%$ DMSO and at pH 3.0 the exchange rate was insignificantly affected, whereas effect was more predominant at higher $\mathrm{pH}$ values. ${ }^{49} \mathrm{In}$ the H/D exchange experiments (see the Methods section) the spectral data were obtained in $\mathrm{D}_{2} \mathrm{O}$ at $\mathrm{pH}$ 3.0, permitting the use of specific proton assignments made earlier by Redfield and Dobson. ${ }^{47}$

Protection factors of the amide protons could be classified into two groups: significant protection is observed from the helical domain of the protein, whereas the triple stranded antiparallel $\beta$-sheet domain is least protected (Fig. 11). The four indole protons also exchange sl owly with solvent. W111 and

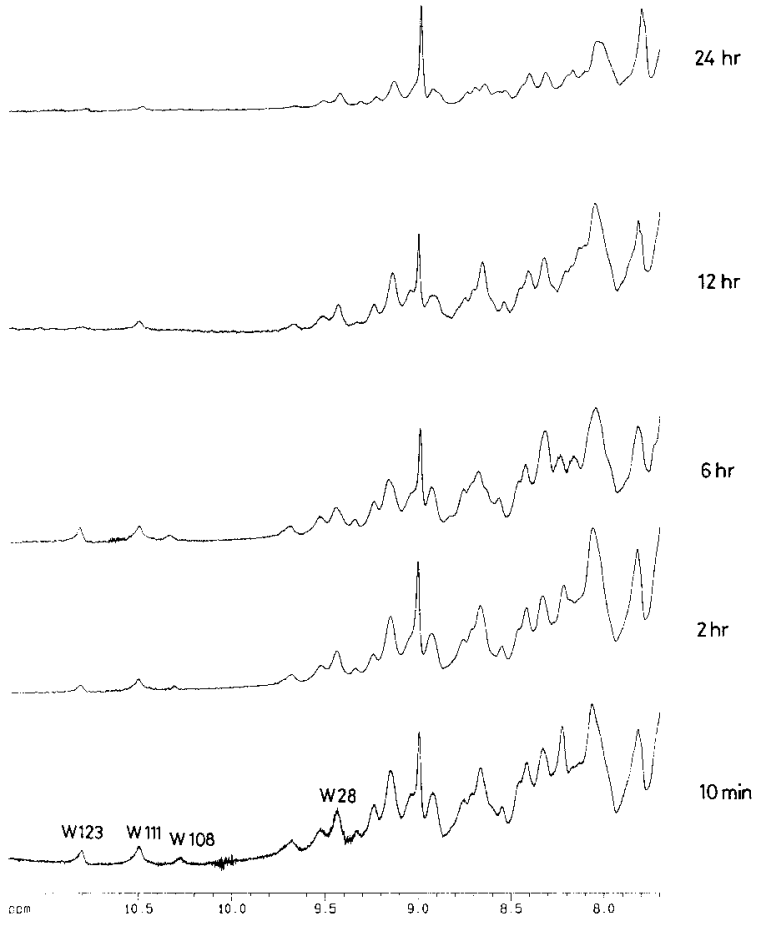

Fig. 12. The low-field region of one-dimensional ${ }^{1} \mathrm{H}$ NMR spectra of lysozyme in $\mathrm{D}_{2} \mathrm{O}$ after refolding at different time points from $50 \%$ DMSO, indicating slowly exchangeable indole resonances and amide protons.

W28 indole protons are not completely exchanged even after 24 hours (Fig. 12). Only N65, R64, R61, and $\mathrm{N} 46$ show relatively high protection factors, for other amide protons of the $\beta$-sheet domain the protection factor was $<10$. The structural integrity of the helical domain in 50\% DMSO appear to be maintained as evidenced by the high protection factor. By contrast, the $\beta$-sheet structural lobe appears predominantly disorganized. Four amide protons from the large loop (64-78) were al so protected, with N65 and C76 having protection factors $\sim 100$. All the helices in the structured DMSO state of lysozymeare not protected to the same extent. Many residues from helix A (5-15), helix $B$ (25-36), and helix D (109-115) have very high protection factors, ranging from 50 to 120 . By contrast, only two amide protons from helix C (88-101) are considerably protected. The most noteworthy feature of the distribution of protection factors in the helical domain is, residues protected in the helices are not only contiguous in the linear sequence but the side chains of those residues form a "core cluster" in the native state structure of Iysozyme (Fig. 13). This cluster comprises many aromatic (W28, W111, W108, W123, Y23, F34) and aliphatic residues and probably contributing largely to the stability of the structured intermediate by hydrophobic interaction (see Discussion section below). 


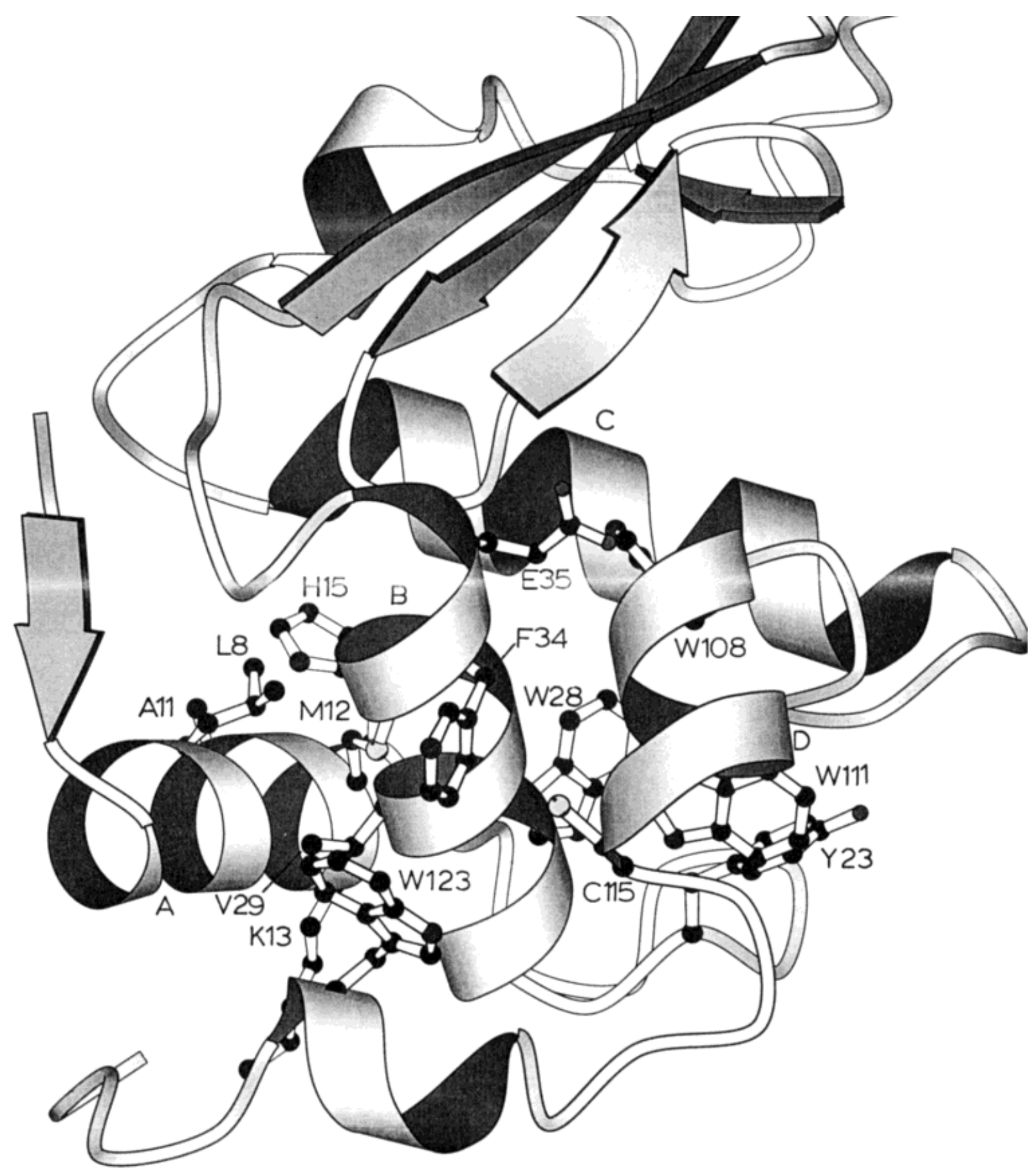

Fig. 13. The native structure of hen lysozyme showing the structured core in the helical domain in 50\% DMSO, which exhibits slow exchange of backbone amide protons. The four major $\alpha$ helices are marked as A (5-15), B (25-36), C (88-101), and D

109-115). The figure has drawn by using the program MOLSCRIPT ${ }^{95}$ (Kraulis, 1991). The part of the loop connecting $\beta$ strands is not shown.

\section{DISCUSSION}

The present study establishes that while lysozyme is largely unfol ded in DMSO a structured intermediate state is formed in 5\% DMSO as characterized by $C D$, fluorescence, $N M R$, and H/D exchange studies.
The partially folded state of lysozyme at 50\% DMSO exhibits an enhanced near-UV CD, burial of the tryptophan residues to ionic quenchers, protection of indole NHs from solvent exchange, the presence of a hydrophobic core in the helical domain and many 
strong NOEs between aromatic and aliphatic side chains. This partially folded state is quite similar to the molten globule state of a $\mathrm{Ca}^{2+}$ depleted equine apo-lysozyme, stabilized at low $\mathrm{pH}$ and low $\left(5^{\circ} \mathrm{C}\right)$ or high $\left(45^{\circ} \mathrm{C}\right)$ temperatures or in $2 \mathrm{M} \mathrm{GuHCl}^{50,62}$ and also resembles the molten globule states of interIukin 4,63 apomyoglobin, 59,64 staphylococcal nuclease, $^{65}$ and cytochrome C. ${ }^{66}$ These states contain somewhat moretertiary interactions, usually termed as "ordered" molten globule states, as compared to the molten gl obule states of $\alpha$-lactalbumin. Further, these intermediate states generally display considerable structural heterogeneity, spanning from an ordered hydrophobic core to a more flexible core arrangement. Our results clearly indicate that compact denatured states induced by classical denaturants, can also be formed by changing solvent conditions, particularly in the presence of specific organic solvents like DMSO. Recently, a globular denatured state of cytochrome c has been reported in aqueous methanol solvent, which is analogous to the wellestablished molten gl obule state in usual denaturing conditions. ${ }^{67,68}$

The structural transition induced by DMSO depends on solvent concentration. At low concentrations of DMSO ( $<8-10 \%)$, the overall structure of the protein is preserved. At these low concentrations NMR data suggest "binding" of DMSO to regions, including the active site, as evident from the chemical shift perturbations of the indole protons in ${ }^{1} \mathrm{H}$ NMR spectra (Fig. 4), concomitant with increases in ellipticities of near-UV CD bands (Fig. 1). These data are consistent with a recent report describing the lowering of surface tension at lysozyme-water interfaces at low DMSO concentrations, an observation that has been interpreted in terms of preferential binding of DMSO to lysozyme via hydrophobic interactions involving the two methyl groups of the solvent. ${ }^{69}$

The ${ }^{1} \mathrm{H}$ NMR spectra of lysozyme in 50\% DMSO show a wider chemical shift dispersion than that observed for random coil polypeptides or the highly unfolded state obtained in $100 \%$ DMSO. However, the chemical shift dispersion is lower in the 50\% DMSO state than in the native state (Fig. 3). The reduction in the chemical shift dispersion is commonly observed with partially unfolded states of many proteins, for example, acid and temperature denatured forms of $\alpha$-lactalbumins, ${ }^{70-72}$ methanol denatured state of ubiqutin at low $\mathrm{pH}^{26}$, acid denatured state of cytochrome c, ${ }^{73}$ 2,2,2-trifluoroethanol denatured state of hen egg white lysozyme ${ }^{28}$ and a partially denatured state of equine lysozyme ${ }^{50}$ suggesting a loss of nativelike tertiary interactions in the partially melted structure.

NOEs between backbone protons are a sensitive probe of protein secondary structure. ${ }^{55}$ NOE SY spectra of lysozyme at $50 \%$ DMSO show at least 30 strong $\mathrm{NH} / \mathrm{NH}$ NOEs (Fig. 7) and few relatively weak $\mathrm{C}^{\alpha} \mathrm{H} / \mathrm{NH}$ NOEs indicative of persistent helical or turn structures, while NOE s diagnostic of $\beta$ sheets are largely absent.

The presence of many highfield methyl resonances and some intense interresidue NOEs between the aromatic ring protons and the side chains of aliphatic residues indicates many tertiary interactions persist in the DMSO state. However, presence of new NOEs from the W28 ring protons to the aliphatic residues, diminished exposure of tryptophans to iodide quenching and intense near-UV CD are also suggestive of tertiary interactions which could be of "nonnative."

The partially unfolded states of many proteins exhibit a strong affinity to fluorescent hydrophobic probe molecules such as ANS, ${ }^{74}$ a consequence of the exposure of the normally buried hydrophobic residues. The interaction of hydrophobic fluorescent probes are accompanied by intensity enhancement and spectral shifts in emission spectra due to changes in the polarity of the microenvironment of the probe. The low solvent polarity of $50 \%$ DMSO- $\mathrm{H}_{2} \mathrm{O}\left(\mathrm{E}_{\mathrm{T}} 56\right)^{75}$ precludes the use of fluorescence spectroscopy to monitor probe binding, since intensity enhancements are not easily observable under such conditions as the quantum yield of free probe is very high. However, the interaction of the probe is amenable to analysis by NMR line-broadening as well as by observation of intermolecular NOEs from the probe to the partially folded protein (Figs. 9 and 10). The ${ }^{1} \mathrm{H}$ NMR resonance lines of ANS and ANSA are broadened when titrated with the protein in $50 \%$ DMSO and intermolecular NOEs are observed from the aliphatic side chains of the protein to the ring protons of ANSA confirming apolar contacts. The binding of hydrophobic molecules to the $50 \%$ DMSO state of lysozyme suggests partial exposure of some hydrophobic residues reminiscent of the molten gl obulelike states of many proteins.

The measurement of protection factors from H/D exchange for as many as 55 protons in the intermediate state of Iysozyme at 50\% DMSO establishes that three of the four helices (A, B, and D) are largely intact, while little or no protection is observed from the short $\beta$-sheet structure (Fig. 11). The uniformly higher protection of the three $\alpha$ helices can be rationalized by a large retention of their nativelike helical structure as well as persistent side-chain contacts between them. Since the residual structure was largely present in the helical domain, we concentrate on the structural organization of the helices in Iysozyme structure. Among the four $\alpha$ helices, helix $B$ is the most hydrophobic in sequence and many of its residues are deeply buried and exchangeslowly in the native state. ${ }^{76} \mathrm{~A}$ large part of the hydrophobic core of protein is formed by the close packing of the side chains from helix $A$ and helix $D$ against helix $B$. Three of the tryptophan residues (W28, W108, and W111) are sequestered in this hydrophobic core 
along with other aromatic and aliphatic side chains. The indole protons as well as amide protons of the tryptophans exchange slowly in the native state as well as in the $50 \%$ DMSO state of Iysozyme. The enhanced near-UV CD signal is also suggestive of a greater degree of immobilization of the side chains. The high degree of protection of many residues in helix A (L8, A10, A11, M12, K13), helix B (W28, V29, A32, F34, E35, S36), and helix D (W108, W111, C115), which are the key residues in the hydrophobic core, strongly suggests a persistent hydrophobic core in the intermediate state of Iysozyme. Y23, which is present as a linker residue between helix $A$ and helix $B$, was also protected, probably due to its aromatic interaction with the tryptophan residues in the slowly exchanging core (Fig. 13). On the other hand, many of the strongly protected amide protons (V92, A95, V99) from helix $C$ have low protection factors in $50 \%$ DMSO, presumably due to fewer tertiary contacts. N onpolar cores stabilized by secondary as well as tertiary interactions appear to be a common feature of many molten globule states and presumably play a dominant role in the stability of the partially folded protein.4,77,78 Local clustering of hydrophobic residues have al so been identified in highly denatured states of proteins. ${ }^{44,79,80}$ Our results also suggest the role of apolar interactions in stabilization of partially folded states, more importantly, specific "nativelike interactions" between residues that are noncontiguous in the polypeptide chain. Hence formation of such nativelike hydrophobic cores would be a energetically highly favorable process due to sequestration of nonpolar residues from polar environments, reducing the search for alternative conformations with the concomitant secondary structure formation intrinsic to the amino acid sequence. 81,82

Kinetic intermediates in the folding pathway of hen lysozyme have been well characterized by different techniques. ${ }^{83,84}$ Equilibrium molten gl obule intermediates of homologous proteins $\alpha$-lactalbumins $21,54,85$ and equine lysozyme ${ }^{50,62}$ have recently been characterized by NMR. It is therefore of interest to compare the intermediate DMSO state of Iysozyme with its kinetic counterparts and the equilibrium intermediates of evolutionary related proteins obtained under classical denaturing conditions. The strikingly common structural features between the early kinetic intermediate and the DMSO state of lysozyme is the substantial protection of the helical domain in both, along with the formation of the "domain core." This is evident from rapid protection of many core-forming residues as well as indole protons of tryptophans in the early phase of the fol ding pathway. Both the intermediates have some exposed nonpolar surface for the binding of hydrophobic probe molecules. However, there are some differences between the kinetic intermediates and the intermediate state of Iysozyme in $50 \%$
DMSO. The helix C, which was marginally protected in DMSO, showed similar protection kinetics like the other three helices (A, B, and D) in the kinetic intermediate. The solvent exposure of the helix $C$ in DMSO state can be attributed to its susceptibility to unfold in denaturing conditions, since the stability of helix $C$ is mainly contributed by its near-neighbor contacts, ${ }^{86}$ with fewer contacts in the helical core. This conjecture is supported by a CD study of the peptide fragments from hen lysozyme in an $\mathrm{H}_{2} \mathrm{O}$ / TFE mixture, which indicated greater helicity in the peptide fragment containing helix C. ${ }^{86} \mathrm{~A}$ detailed study of lysozyme in $50 \%$ TFE by Buck et al. ${ }^{28}$ shows that there is a large increase in far-UV CD, with limited protection of core residues and tryptophan indole protons. The TFE denatured state is presumably a coil like intermediate state with very little side-chain interactions, which is distinct from the compact molten gl obulelike state. ${ }^{38,87,88} \mathrm{~A}$ potentially intriguing observation in the present study is the enhanced near-UV CD signal in 50\% DMSO suggesting nonnative interactions between aromatic residues. Nonnative interactions have been observed in far-UV CD and tryptophan fluorescence in the kinetic experiments with lysozyme, ${ }^{25,89}$ indicating a probable role in stabilizing the folding intermediates. ${ }^{90,91}$

The partly folded state of hen Iysozyme in 50\% DMSO also shares many common features with the molten globule state of the structurally homologous proteins $\alpha$-lactalbumins and equine lysozyme. The molten globule form of both the proteins largely retain the helical structure with the preferential unfolding of the helix $\mathrm{C}$. The molten globule state of equine lysozyme has a marked similarity with the intermediate state of lysozyme in 50\% DMSO. The molten globule state of the equine protein also possesses an enhanced near-UV CD band and an analogous slowly exchanging hydrophobic core composed of three helices. It has been pointed out the slow-exchange hydrophobic core could probably be the "protein folding core," 92 which presumably forms first in the folding process via "hydrophobic zipping," 81 creating sites for the secondary structure formation. Structural analysis of the intermediate states of lysozymes and $\alpha$-lactalbumins obtained under diverse denaturing conditions suggests that formation of such "core structure" encompassing the helical domain is likely to be a common feature of their folding mechanism. Identification of such independent structural cores in stable intermediatestates will have great importance for designing smaller proteins with nativelike structural properties. Recently, large peptides corresponding to the helical domain of human $\alpha$-lactal bumin have been shown to retain nativelike three-dimensional folds in an overall molten globulelike conformation. ${ }^{93,94}$ In conclusion, our results permit characterization of an ordered equilibrium intermediate state of hen lysozyme 
in $50 \%$ DMSO, emphasizing the potential use of nonaqueous solvents in stabilizing partly folded state of protein.

\section{ACKNOWLE DGMENTS}

All NMR studies were performed at the Sophisticated I nstruments Facility, I ndian Institute of Science. We thank K. Gunasekaran for help in preparing Figure 13.

\section{REFERENCES}

1. Creighton, T.E. "Protein Folding." New York: W.H. Freeman, 1992.

2. Kim, P.S., Baldwin, R.L. Intermediates in the folding reactions of thesmall proteins. Annu. Rev. Biochem. 59:631660, 1990.

3. Fink, A.L. Compact intermediate states in protein folding. Annu. Rev. Biophys. Biomol. Struct. 24:495-522, 1995.

4. Privalov, P.L. Intermediatestates in protein folding. J . Mol. Biol. 258:707-725, 1996

5. Creighton, T.E. (1990). Protein folding. Biochem. J . 270:115, 1990.

6. Dobson, C.M. Characterization of protein folding intermediates. Curr. Opin. Struct. Biol. 1:22-27, 1991.

7. Kim, P.S., Baldwin, R.L. Specific intermediates in the folding reactions of small proteins and the mechanism of protein folding. Annu. Rev. Biochem. 51:459-489, 1982.

8. Creighton, T.E. (1984). Disulfide bond formation in proteins. Methods Enzymol. 107:305-329, 1984.

9. Roder, H., Elove, G.A., Englander, S.W. Structural characterization of folding intermediates in cytochrome c by $\mathrm{H}$-exchange labeling and proton NMR. Nature 336:700704, 1988.

10. Udgaonkar, J .B., Baldwin, R.L. (1989). NMR evidence for an early framework intermediate on the fol ding pathway of ribonucleaseA. Nature 335:694-699, 1989.

11. Hughson, F.M., Wright, P.E., Baldwin, R.L. Structural characterization of a partly fol ded apomyogl obin intermediate. Science 249:1544-1548, 1992.

12. Sosnick, T.R., Mayne, L., Hiller, R., Englander, S.W. The barriers in protein folding. Nature Struct. Biol. 1:149-156, 1994.

13. Dill, K.A., Shortle, D. Denatured states of proteins. Annu. Rev. Biochem. 60:795-825, 1991.

14. Christen, H., Pain, R.H. Molten gl obule intermediates and protein folding. Eur. Biophys. J . 19:221-229, 1991.

15. Dobson, C.M. Unfolded proteins, compact states and molten gl obules. Curr. Opin. Struct. Biol. 2:6-12, 1992.

16. Ptitsyn, O.B. Molten globule and protein folding. Adv. Protein Chem. 47:83-229, 1995.

17. Chen, X., Rambo, R., Matthews, C.R. Amino acid replacements can selectively affect the interaction energy of autonomous folding units in the $\alpha$ subunit of tryptophan synthase. Biochemistry 31:2219-2223, 1992.

18. Sanz, M.J., Fersht, A.R. Rationally designing the accumulation of a folding intermediate of barnase by protein engineering. Biochemistry 32:13584-13592, 1993.

19. Nath, U., Udgaonkar, J .B. Perturbation of a tertiary hydrogen bond by mutagenesis of the sole his residue to gln leads to accumulate of at least one equilibrium fol ding intermediate. Biochemistry 34:1702-1713, 1995.

20. Klibanov, A.M. (1989). Enzymatic catalysis in anhydrous organic solvents. Trends Biochem. Sci. 14:141-144, 1989.

21. Kuwajima, K. The molten globule state as a clue for understanding the folding and cooperativity of globularprotein structure. Proteins 6:87-103, 1989.

22. Dobson, C.M., Evans, P.A. Protein folding kinetics from magnetization transfer nuclear magnetic resonance. Biochemistry 23:4267-4270, 1984.

23. Kuwajima, K., Hirao, Y., Ikeguchi, M., Sugai, S. Compari- son of the transient folding intermediates in lysozyme and $\alpha$-lactalbumin. Biochemistry 24:874-881, 1985.

24. Miranker, A., Radford, S.E., Karplus, M., Dobson, C.M. Demonstration by NMR of folding domains in lysozyme. Nature 349:633-636, 1991.

25. Radford, S.E., Dobson, C.M., Evans, P.A. The folding of hen lysozyme involves partially structured intermediates and multiple pathways. Nature 358:302-307, 1992.

26. Harding, M.M., Williams, D.H., Woolfson, D.N. Characterization of a partially denatured state of a protein by two-dimensional NMR: Reduction of the hydrophobic interactions in ubiqutin. Biochemistry 30:3120-3128, 1991.

27. Fan, P., Bracken, C., Baum, J . Structural characterization of monellin in the alcohol-denatured state by NMR: Evidence for $\beta$-sheet to $\alpha$-helix conversion. Biochemistry 32: 1573-1582, 1993.

28. Buck, M., Radford, S.E., Dobson, C.M. A partially folded state of hen egg white lysozyme in trifluoroethanol: Structural characterization and implication for protein folding. Biochemistry 32:669-678, 1993.

29. Alexandrescu, A.T., Ng, Y.-L., Dobson, C.M. Characterization of a trifluoroethanol induced partially folded state of $\alpha$-lactalbumin. J . Mol. Biol. 235:587-599, 1994.

30. Nelson, J.W., Kallenbach, N.R. (1989). Persistence of the $\alpha$-helix stop signal in the S-peptide in trifluoroethanol solutions. Biochemistry 28:5256-5261, 1989.

31. Bruch, M.D., Dhingra, M.M., Gierasch, L.M. Side-chain backbone hydrogen bonding contribution to helix stability in peptides derived from an $\alpha$-helical region of carboxypeptidase A. Proteins 10:130-139, 1992.

32. Dyson, H.J ., Merutka, G., Waltho, J .P., Lerner, R.A., Wright, P.E. Folding of peptide fragments comprising the complete sequence of proteins: Models for initiation of protein folding. I. Myohemerythrin. J . Mol. Biol. 226:795-817, 1992.

33. Sonnichsen, F.D., Van Eyk, J .E., Hodges, R.S., Sykes, B.D. Effect of trifluoroethanol on protein structure: An NMR and CD study using a synthetic actin peptide. Biochemistry 31:8790-8798, 1992.

34. Segawa, S.I., Fukuno, T., Fujiwara, K., Noda, Y. Local structures in unfolded lysozyme and correlation with secondary structures in the native conformation: Helixforming or -breaking propensity of peptide segments. Biopolymers 31:497-509, 1991.

35. Dufour, E., Haertle, T. Alcohol-induced changes of $\beta$ lactoglobulin-retinol binding stoichiometry. Protein Eng. 4:185-190, 1990.

36. J ackson, M., Mantsch, H.H. Halogenated alcohols as solvents for proteins: FTIR spectroscopic studies. Biochim. Biophys. Acta 1118:139-143, 1992.

37. Wang, J .M., Takeda, A., Yang, J .T., Wu, C.-S.C. Conformation of concanavalin $A$ and its fragments in aqueous solution and organic solvent-water mixtures. J. Protein Chem. 11:157-164, 1992.

38. Shiraki, K., Nishikawa, K., Goto, Y. Trifluoroethanolinduced stabilization of the $\alpha$-helical structure of $\beta$ lactogl obulin: I mplication for non-hierarchical protein folding. J. Mol. Biol. 245:180-194, 1995.

39. Singer, S.J. The properties of proteins in nonaqueous solvents. Adv. Protein Chem. 17:1-68, 1962.

40. Karle, I.L., Flippen-Anderson, L.J ., Uma, K., Balaram, P. Unfolding of an $\alpha$-helix in peptide crystal by solvation: Conformational fragility in a hepta peptide. Biopolymers 33:827-837, 1993.

41. Rosemann, M., J encks, W. Interaction of urea and other polar compounds in water. J. Amer. Chem. Soc. 97:631640, 1975

42. Lehmann, S.M., Stansfield, R. Binding of dimethyl sulfoxide to lysozyme in crystals, studied with neutron diffraction. Biochemistry 28:7028-7033, 1989.

43. Hoven, G. The solubility of proteins in organic solvents. Acta Chem. Scand. 50:68-70, 1996.

44. Evans, P.A., Topping, K.D., Woolfson, D.N., Dobson, C.M. Hydrophobic clustering in the non-native states of a pro- 
tein: Interpretation of chemical shifts in NMR spectra of denatured states of lysozyme. Proteins 9:248-266, 1991.

45. J ackson, M., Mantsch, H.H. Beware of proteins in DMSO. Biochim. Biophys. Acta 1078:231-235, 1991.

46. Hamaguchi, K. Structure of muramidase (lysozyme). VIII Effect of dimethylsulfoxide on the stability of muramidase. Biochem. J . 56:441-449, 1964.

47. Redfield, C., Dobson, C.M. Sequential ${ }^{1} \mathrm{H}$ NMR assignment and secondary structure of hen egg white lysozyme in solution. Biochemistry 27:122-136, 1988.

48. Bai, Y., Milne, J.S., Mayne, L., Englander, S.W. Primary structure effects on peptide group hydrogen exchange. Proteins 17:75-86, 1993

49. Zang, Yu-Zhu, Paterson, Y., Roder, H. Rapid amide proton exchange rates in peptides and proteins measured by solvent quenching and two-dimensional NMR. Protein Sci. 4:804-814, 1995

50. Deal, H.V., Haezebrouck, P., Morozova, L., Arico-Muendel, C., Dobson, C.M. Partially fol ded states of equinelysozyme: Structural characterization and significance for protein folding. Biochemistry 32:11886-11894, 1993.

51. Morozova, L., Haezebronck, P., Cauwelaert, V.F. Stability of equine lysozyme. Biophys. Chem. 41:185-191, 1991.

52. Broadhurst, R.W., Dobson, C.M., Hore, P.S., Radford, S.E., Ress, M.L. A photochemically induced dynamic nuclear polarization study of denatured states of lysozyme. Biochemistry 30:405-412, 1992.

53. Lehrer, S.S. Solute perturbation of protein fluorescence: The quenching of the tryptophyl fluorescence of the model compounds and of Iysozyme by iodide ion. Biochemistry 10:3254-3263, 1971.

54. Baum, J., Dobson, C.M., Evans, A.P., Hanley, C. (1989). Characterization of a partly folded protein by NMR methods: Studies on the molten globule state of guinea pig $\alpha$-lactal bumin. Biochemistry 28:7-13, 1989.

55. Wüthrich, K. "NMR of Proteins and Nucleic Acids." New York: Wiley, 1986.

56. Wishart, D.S., Syke, B.D., Richards, F.M. Relationship between nuclear magnetic resonance chemical shift and protein secondary structure. J. Mol. Biol. 222:311-333, 1991.

57. Lumb, K.J ., Dobson, C.M. ${ }^{1} \mathrm{H}$ nuclear magnetic resonance studies of the interaction of urea with hen lysozyme: Origin of the conformational changes induced in hen lysozyme by $\mathrm{N}$-acetylglucosamine oligosaccharides. J . Mol. Biol. 227:9$14,1992$.

58. Dyson, H.J ., Rance, M., Houghten, R.A., Wright, P.E., Lerner, R.A. Folding of immunnogenic peptide fragments of proteins in water solution. J. Mol. Biol. 201:201-217, 1988.

59. Baldwin, R.L. Pulsed H/D exchange studies of folding intermediates. Curr. Opin. Struct. Biol. 3:84-91, 1993.

60. Molday, R.S., Englander, S.W., Kallen, R.G. Primary structure effects on peptide groups hydrogen exchange. Biochemistry 11:150-158, 1972.

61. Englander, S.W., Kallenbach, N.R. Hydrogen exchange and structural dynamics of proteins and nucleic acids. Q. Rev. Biophys. 16:521-655, 1984.

62. Morozova, L., Haynie, D.T., Arico-Muendel, C., Deal, H.V., Dobson, C.M. Structural basis of the stability of a molten gl obule. Nature Struct. Biol. 2:871-875, 1995.

63. Redfield, C., Smith, R., Dobson, C.M. Structural characterization of a highly-ordered "molten globule" at low pH. Nature Struct. Biol. 1:23-29, 1994.

64. Lin, L., Pinker, R.J., Rose, G.D., Kallenbach, N.R. Molten gl obule characteristics of the native state of apomyoglobin. Nature Struct. Biol. 1:447-451, 1994.

65. Shortle, D. The denatured state (the other half of the folding equation) and its role in protein stability. FASEB J . 10:27-34, 1996.

66. Kuroda, Y., Kidokoro, S., Wada, A. Thermodynamic characterization of cytochrome $\mathrm{c}$ at low $\mathrm{pH}$, observation of the molten globule state and of the cold denaturation process. J . Mol. Biol. 223:1139-1153, 1992.
67. Kamatari, Y.O., Konno, T., Kataoka, M., Akasaka, K. The methanol-induced gl obular and expanded denatured states of cytochrome c: A study by CD, fluorescence, NMR, and small-angle x-ray scattering. J. Mol. Biol. 259:512-523, 1996.

68. Bychkova, V.E., Dujsekina, A.E., Klenin, S.I., Tiktopulo, E.I., Uversky, V.N., Ptitsyn, O.B. Molten globule-like state of cytochrome c under conditions simulating those near the member surface. Biochemistry 35:6058-6063, 1996.

69. Kita, Y., Arakawa, T., Lin, T-Y., Timasheff, S.N. Contribution of the surface free energy perturbation to proteinsolvent interactions. Biochemistry 33:15178-15189, 1994.

70. Kuwajima, K., Harushima, Y., Sugai, S. Influence of $\mathrm{Ca}^{2+}$ binding on the structure and stability of bovine $\alpha$ lactalbumin studied by circular dichroism and nuclear magnetic resonance spectra. Int. J. Peptide Protein Res. 27:18-27, 1986.

71. I keguchi, M., Kuwajima, K., Mitani, M., Sugai, S. Evidence for the identity between the equilibrium unfolding intermediate and a transient folding intermediate: A comparative study of the folding reactions of $\alpha$-lactalbumin and lysozyme. Biochemistry 25:6965-6972, 1986.

72. Alexandrescu, A.T., Evans, P.A., Pitkeathly, M., Baum, J ., Dobson, C.M. Structure and dynamics of acid denatured molten globule state of $\alpha$-lactalbumin: A two-dimensional NMR study. Biochemistry 32:1707-1718, 1993.

73. J eng, M-F., Englander, S.W. Stable submolecular folding units in a non-compact form of cytochrome c. J. Mol. Biol. 221:1045-1061, 1991

74. Semisotnov, G.V., Rodionova, N.A., Razgulyaev, O.T., Uversky, V.N., Gripas, A.F., Glimanshim, R.I. Study of the "molten globule" intermediate state in protein folding by a hydrophobic fluorescent probe. Biopolymers 31:119-128, 1991.

75. Ransdell, A.R., Wamser, C.C. Solvent and substituents effect on the redox potentials of free-base tetraphenylporphyrins in DMSO and aqueous DMSO. J. Phys. Chem. 96:10572-10575, 1992.

76. Radford, S.E., Buck, M., Topping, K.D., Dobson, C.M., Evans, P.A. Hydrogen exchange in native and denatured states of hen egg-white lysozyme. Proteins 14:237-248, 1992

77. Freire, E. Thermodynamics of partly folded intermediates in proteins. Annu. Rev. Biophys. Biomol. Struct. 24:1-16, 1995

78. Ptitsyn, O.B. How molten is the molten globule? Nature Struct. Biol. 3:488-490, 1996

79. Neri, D., Billeter, M., Wider, G., Wüthrich, K. (1992). NMR determination of residual structure in a urea-denatured protein, the 434-repressor. Science 257:1559-1563, 1992.

80. Lumb, K.J., Kim, P.S. Formation of a hydrophobic cluster in a denatured bovine pancreatic trypsin inhibitor. J. Mol. Biol. 236:412-420, 1994.

81. Dill, K.A., Fiebig, K., Chan, H.S. Cooperativity in proteinfolding kinetics. Proc. Natl. Acad. Sci. U.S.A. 90:19421946, 1993.

82. Sali, A., Shakhnovich, E., Karplus, M. How does a protein fold? Nature 369:248-251, 1995

83. Radford, S.E., Dobson, C.M. Insight into protein folding using physical techniques: Studies of Iysozyme and $\alpha-$ lactal bumin. Phil. Trans. R. Soc. Lond. B 384:17-25, 1995.

84. Dobson, C.M., Evans, P.A., Radford, S.E. Understanding how proteins fold: The lysozyme story so far. Trends Biochem. Sci. 19:31-37, 1994.

85. Schulman, B.A., Redfield, C., Peng, Z., Dobson, C.M., Kim, P.S. Different subdomains are most protected from hydrogen exchange in the molten globule and native states of human $\alpha$-lactalbumin. J . Mol. Biol. 253:651-657, 1995.

86. Yang, J.J ., Buck, M., Pitkeathly, M., Kotik, M., Haynie, D.T., Dobson, C.M., Radford, S.E. Conformational properties of four peptides spanning the sequence of hen lysozyme. J . Mol. Biol. 252:483-491, 1995.

87. Buck, M., Schwalbe, H., Dobson, C.M. Characterization of conformational preferences in a partly folded protein by 
heteronuclear NMR spectroscopy: Assignment and secondary structure analysis of hen egg-white lysozyme in trifluoroethanol. Biochemistry 34:13219-13232, 1995.

88. Buck, M., Schwalbe, H., Dobson, C.M. Main-chain dynamics of a partially folded protein: ${ }^{15} \mathrm{~N}$ NMR relaxation measurements of hen egg white lysozyme denatured in trifluoroethanol. J . Mol. Biol. 257:669-683, 1996.

89. Chaffote, A.F., Guillou, Y., Goldberg, M.E. Kinetic resolution of peptide bond and side chain far-UV circular dichroism during the fol ding of hen egg white lysozyme. Biochemistry 31:9694-9702, 1992.

90. Creighton, T.E. The energetic ups and downs of protein folding. Nature Struct. Biol. 1:135-138, 1994.
91. Hua, X.Q., Gozani, N.S., Chance, E.R., Hoffmann, A.J., Frank, H.B., Weiss, A.M. Structure of a protein in a kinetic trap. Nature Struct. Biol. 2:129-138, 1995.

92. Woodward, C. Is the slow exchange core the protein folding core? Trends Biochem. Sci. 18:359-360, 1993.

93. Peng, Z., Kim, P.S. A protein dissection study of a molten globule. Biochemistry 33:2136-2141, 1994.

94. Wu, L., Peng, Z., Kim, P.S. Bipartite structure of the $\alpha$-lactalbumin molten globule. Nature Struct. Biol. 2:281286, 1995.

95. Kraulis, P.J. MOLSCRIPT: A program to produce both detailed and schematic plots of protein structures. J . Appl. Crystallogr. 24:946-950, 1991. 